\title{
ILIE CONSTANTIN, ÉCRIVAIN DE LA LITTÉRATURE ROUMAINE DE L'EXIL
}

\author{
ILIE CONSTANTIN, WRITER OF ROMANIAN \\ LITERATURE OF EXILE
}

\section{Dan Constantin STERIAN ${ }^{1}$}

https://doi.org/10.52744/9786062613242.11

Résumé : Par les thèmes et la problématique de ses écrits, Ilie Constantin est un écrivain apprécié par la critique littéraire française ; en même temps, il est aussi l'une des figures essentielles de la littérature roumaine de l'exil. Le thème de l'exil traverse comme un fil rouge la littérature d'expression française de Constantin : il est à la fois une source d'inspiration et une cause d'ennui et de désespoir. Il hante en particulier le recueil Le lettré barbare, dont les poèmes « Délivré de l'attente », "Quand il n'est plus de voix » ou « Les Poètes de l'exil » sont les plus illustratifs.

Mots-clés : Exil ; Littérature d’expression française ; Poésie ; Roman.

\begin{abstract}
Due to the themes and issues dealt with in his writing, Ilie Constantin is a writer whom French literary critics praised. At the same time, he is also one of the essential figures of the Romanian literature of exile. The theme of exile runs like a thread through Constantin's writings in French: it is both a source of inspiration and a cause of boredom and despair. It haunts in particular the collection Le lettré barbare, whose poems "Rescued from waiting" ("Délivré de l'attente"), "When there are no more voices" ("Quand il n'est plus de voix") or "The Poets of exile" ("Les Poètes de l'exil") are the most illustrative.
\end{abstract}

Keywords: Exile; Literature of French Expression; Poetry; Novel

1 Faculté des Lettres, Université Spiru Haret, dan.sterian@spiruharet.ro, constantin.sterian@yahoo.fr 
Les poètes de l'exil tirent du néant, sans trêve, des seaux de soif. Ils errent dans un désert boueux,/fait d'oubli, et, tant qu'ils ont pied, ils pataugent dans la mer où finissent toutes les berges. Les poètes de l'exil jettent des sondes dans l'abîme comme dans

l'ailleurs, et de partout ils tirent des seaux de soif.

Constantin, « Les Poètes de l'exil », dans Le Lettré barbare,

1994

\section{Quelques repères biographiques}

À côté d'autres écrivains roumains consacrés tels que Ana Blandiana, Cezar Baltag, Nichita Stănescu, Ilie Constantin appartient à la génération des écrivains roumains des années 60 qui, dans le contexte d'un relatif dégel idéologique, sont revenus aux modèles lyriques de l'entre-deux-guerres : ils libèrent la poésie de toute oppression idéologique tout en la remplissant d'images insolites. Les thèmes de la résurrection et du paradoxe vont de pair dans leur poésie.

Issu d'une famille modeste, Ilie Constantin est né le 16 février 1939 à Bucarest. Il étudie au lycée Sfântul Sava (1953 - 1956), puis à la Faculté des Lettres de l'Université de Bucarest (1956 - 1961) où il suit, en particulier, des cours de littérature italienne. Il commence timidement à écrire des vers pour la revue Tânărul scrïtor (Le Jeune Écrivain) en tant qu'étudiant. Sa véritable carrière littéraire débute avec le recueil de poèmes Vântul cutreieră apele (Le Vent rôde par-dessus les eaux, 1960), salué par Alexandru Philippide qui signe même la préface.

Après ses études universitaires, de 1962 jusqu'en 1965, il est rédacteur du journal Scânteia ; de 1965 jusqu'en 1967, il travaille au Studio Cinématografique de Bucarest, tandis que de 1967 jusqu'en 1974, on le trouve à la tête de la revue littéraire Luceafărul (Hypérion). En 1970 il reçoit le Prix de Poésie de l'Union des Écrivains de Roumanie pour son volume Coline cu demoni (Collines aux démons). 1974 marque le moment où il se décide pour l'exil : il s'établit à Paris, où, malgré des difficultés matérielles, il poursuit son activité littéraire en changeant de langue : il devient un écrivain de langue française. Il continue néanmoins à collaborer avec quelques revues roumaines, telles România literara ( $L a$ Roumanie littéraire), Luceafarul (Hypérion), Viața Româneasca (La Vie Roumaine), Tribuna (La Tribune), Steaua (L'Étoile).

Après avoir soutenu sa thèse La Complicité fertile - Poètes roumains, 1951 - 1973, Ilie Constantin reçoit le titre de docteur ès lettres de l'Institut National de Civilisations et Langues orientales de Paris (1991). Il collabore aux Cahiers de l'Est et publie en français : L'Ailleurs (Silex, 1983), Rivage antérieur (Le Méridien, 1986) et Le Lettré barbare 
(Saint-Germain des Près, 1994). Ses principaux motifs sont l'autre et l'ailleurs ; il les développe en particulier dans La Chute vers le zénith (Gallimard, 1989), transposition d'un conte roumain qui est en fait la parabole du voyage considéré comme expérience initiatique.

Ilie Constantin, outre l'écriture, s'est aussi consacré à la traduction : il a notamment traduit en français des textes d'importants poètes roumains de l'après-guerre (Poètes roumains, anthologie, Bucarest, Éditions de la Fondation Culturelle Roumaine, 1996, en deux volumes).

En tant que traducteur de l'italien au roumain, tâche où il se montre très performant grâce à sa formation d'italianiste, Ilie Constantin se distingue d'abord par une première anthologie de poèmes extraits des volumes d'Eugenio Montale, parue en 1967 aux éditions Tineretului sous le titre de Versuri; une deuxième anthologie paraît en 1970, contenant une sélection de 131 textes d'Umberto Saba, intitulée Canţonierul, Poezii alese (Le Chansonnier : Poèmes choisis) et précédée d'une préface d'Edgar Papu louant largement les choix du traducteur ; Ilie Constantin met ensuite encore à disposition du public roumain une anthologie de la lyrique italienne du $\mathrm{XX}^{\mathrm{e}}$ siècle, qui a pour titre Cântecele altora (Les Chants des autres, 1972, 2003).

En 2002, Ilie Constantin revient définitivement en Roumanie, et il reçoit la même année le Prix National de Poésie " Mihai Eminescu » (Opera Omnia), qui témoigne de ce que sa présence dans le paysage littéraire roumain est considérée comme vitale. Constantin, en effet, et contrairement à d'autres auteurs roumains partis en exil, a pu aisément être récupéré par la littérature roumaine car, d’une part, il n'a jamais cessé d'écrire en roumain pendant son exil, ce dont son pays lui a été reconnaissant, et d'autre part, dès son retour, il s'est immédiatement remis à écrire de la poésie en roumain (pensons par exemple à Mulțimea singurătate en 2003). Constantin meurt le 5 février 2020 à Bucarest.

\section{Vers une littérature de l'exil}

L'activité littéraire de Constantin précédant l'exil avait été déjà très fertile, que ce soit en tant que poète - voir les recueils Vântul cutreiera apele (Le vent parcourt les eaux) en 1969, Desprinderea de țărm (S'arracher au rivage) en 1964 ; Clepsidra (Clepsydre) en 1966 , Bunavestire (L'Annonciation) en 1968, Fiara (Le Fauve) en 1969, ou encore Coline cu demoni (Collines aux démons), en 1969 -, en tant que prosateur - voir les romans Tinerii noștri bunici (Nos jeunes grandparents) en 1967 , Câinele înlăcrimat (Le chien en larmes) en 1970, et Vacanța, o plecare (Les vacances, un départ) en 1973 -, en tant que critique littéraire - Despre poeți (Sur les poètes) en 1971, Despre prozatori si critici (Sur les prosateurs et les critiques) en 1972, A doua 
carte despre poeți (Le second livre sur les poètes) en 1973 -, et également en tant que traducteur. Puis lors de son exil, il publie en français les volumes de poésie L'Ailleurs (1983), Rivage antérieur (1986), Le lettré barbare (1994) et le roman La Chute vers le zénith (1989).

En revenant en Roumanie, Constantin, outre sa nouvelle production en roumain, publie aussi quelques recueils bilingues (français-roumains) de poèmes qui complètent son parcours littéraire d'écrivain roumain d'expression française : Le marchand de sabres (Neguțătorul de săbii), en 1997, La rădăcinile depărtării (Aux racines du lointain) en 1999, Limba imperiului (La langue de l'empire), en 2003.

Les volumes de vers publiés avant 1973 en Roumanie aussi bien que ceux publiés lors de son exil en France, sont caractérisés par l'expression d'un moi lyrique profond-paradoxiste souligné par le critique littéraire Ion Pop, qui parle d'une « vague de résurrection paradoxale » (Pop 1973, 156). Selon ce même critique, l'exploitation de la mémoire, le jeu des signifiants et des signifiés, la postulation de ce moi entre les limites du tragisme ou de l'existentialisme produit dans sa poésie des effets d'aliénation et d'angoisse :

De la terre, un cri m'est arrivé,

mes mains se meuvent sur mon visage

engourdies par les larmes-

et qui me croira?

Quelle vaine chute de neige m'entraîne?

La terre a été déchirée par une voix, et nul homme n'est là, dans le monde!

Mes jours sont des gouttes de vin versées à la mémoire des morts.

Bûcher de culpabilité, ma vie chavire sous la neige inutile et sans pureté.

Din pământ, un strigăt/ De la terre, un cri

(Constantin 1995)

Le critique Ion Pop souligne également les accents paradoxaux de la création poétique de Constantin, surtout dans le volume Des Collines aux démons (Coline cu demoni) de 1971, où le poète construit l'image des « collines aux démons » sur une opposition évidente, "véritable métaphore de l'acte même de création, compris et vu comme apprivoisement en formes parfaites des impulsions obscures de l'âme, harmonisation par contemplation du chaos intérieur $»^{2}$ :

${ }^{2}$ Ibid. 
Fils du crépuscule je me sens, oppressé

par le long vacarme de solitude:

le monde se déchaîne autour de moi,

seuls les démons des collines se taisent.

Mais leur corps n'est pas à contempler

leur souffle peut brûler le monde des sphères

et les voir sur les collines amène

leur lent, irréparable dépérissement.

Coline cu demoni/ Des collines aux démons

(Constantin 1969)

La problématique de l'exil chez Constantin est exprimée avec force dans le volume Le lettré barbare, et en particulier dans les poèmes « Délivré de l'attente », «Quand il n'est plus de voix » ou « Les Poètes de l'exil ». L'écriture de cette époque rejoint l'écriture de l'exil que l'on peut trouver chez d'autres poètes de la même génération, tels que Ion Caraion, George Uscătescu, Monica Lovinescu : il s'agit d'une littérature du deuil et du ressentiment. L'écrivain en exil n'est pas réduit au silence ni à l'oubli ; au contraire, il réintègre dans l'imaginaire son pays grâce au travail de la mémoire et à la vigueur de cette nouvelle langue, le français dans le cas de l'écrivain Ilie Constantin. Dans la préface du recueil L'ailleurs, Virgil Tanase écrit :

Le dépaysement devient une épreuve de vérité, l'exil un acte d'allégeance à l'esprit de la poésie. Pourtant l'œil qui fréquente les paysages sentimentaux d'Ilie Constantin pour consigner une géographie faite de déchirements et de départs tragiques, d'éloignement irréversibles et de démembrements funestes, arrive à se demander si le destin de l'homme est ici le moteur ou la victime de la poésie. Car son discours poétique vient nous parler d'une chair qui porte en soi les grands déséquilibres cosmiques et qui de ce fait se trouve à l'origine même de notre vouloir-parler : la pérégrination est le modèle du poétique. (Constantin 1983, 9)

La thématique de l'exil est d'ailleurs inhérente à la littérature d'expression française de Constantin : elle joue le rôle à la fois de source d'inspiration et de cause d'ennui et de désespoir :

Les poètes de l'exil tirent du néant, sans trêve, des seaux de soif.

Ils errent dans un désert boueux, fait d'oubli, et, tant qu'ils ont pied, ils pataugent dans la mer

où finissent toutes les berges. 
Les poètes de l'exil jettent des sondes dans l'abîme comme dans l'ailleurs, et de partout ils tirent des seaux de soif.

« Les Poètes de l'exil », dans Le Lettré barbare

(Constantin 1994)

Peu à peu cependant, le poète réussit à dépasser cette première crise de tristesse provoquées par l'exil justement grâce à son nouvel instrument de travail, la langue française. Il avoue dans un récent interview ${ }^{3}$ qu'après avoir appris en profondeur la langue française et s'être senti prêt pour poursuivre son métier dans cette langue, il s'est aussitôt lancé dans l'écriture, considérant qu'il n'y a pas de différences entre ses deux voix poétiques, la roumaine et la française, « qu'il n'était pas d'abord un poète en roumain et puis un autre en français ».

Si Constantin s'engage dans la « francité » en recourant au français comme forme d'expression, la francité imprègne parfois aussi le contenu de ses poèmes. Son poème Le Français est un hommage rendu à cette deuxième langue grâce à laquelle il peut continuer à écrire :

Il y a quarante ans, en m'affublant

des premières lunettes de ma mère,

mes yeux rieurs d'adolescent

m'ont pas tardé à pleurer, investis

par le bref et opaque avenir de l'horizon.

Loin dans l'âge et sur le continent, je m'abîme dans la claire tendresse qui, de l'au-delà, me soutient dans le monde.

Et parfois je parle à ma mère

dans cette langue que je n'ai pas apprise d'elle.

« Le Français », dans La langue de l'Empire

(Constantin 2000)

\section{Le roman-conte La Chute vers le zénith}

Son roman en français La Chute vers le zénith (1989), couronné par le Grand Prix du Livre Jeunesse de la Société des gens de lettres de France, le consacre comme l'un des écrivains roumains d'expression française les plus importants de l'exil. Il continue à broder sur des motifs qui lui sont chers, tels l'autre et l'ailleurs. Ce roman raconte comment, au XVII ${ }^{e}$ siècle, un enfant regimbe à sortir du ventre de sa mère, sous

\footnotetext{
3 Interview enregistrée sous l'égide du Musée National de la Littérature Roumaine, série "Amintiri din prezent » / Mémoires du présent, animée par Ofelia Creția, disponible sur https://youtu.be/_yDB2GG2kL4
} 
prétexte qu'il lui faut d'abord obtenir de son père la promesse de lui donner « la jeunesse sans vieillesse et la vie sans mort » (Constantin 1989). Cette promesse reçue, Christophe de Quatremonts peut naitre. Il est élevé par Melchior Melzi, figure au savoir inquiétant, qui prophétise que vingt ans après sa mort, il entreprendra un voyage initiatique : la chute vers le zénith. Inspiré d'un conte de fées roumain intitulé $L a$ jeunesse sans vieillesse et la vie sans mort, qui donne son titre au chapitre IX, ce récit est à la fois un roman de cape et d'épée et le lieu d'une profonde réflexion sur l'immortalité. L'auteur définit son récit comme étant « un petit roman-conte de fée un peu ésotérique $\gg 4$.

L'épigraphe du roman est d'ailleurs un fragment d'un conte de fées roumain traditionnel transposé dans le milieu conventionnel de la France des XVIIe et XVIIIe siècles. Ce fragment, tiré des Légendes et contes de fée roumains réunis par Petre Ispirescu, sert d'intertexte premier au roman, et sa fonction est d'indiquer l'esprit et le ton de l'œuvre placée sous son égide :

Et il lui fit bien d'autres promesses de cette sorte. Enfin, voyant qu'il ne pouvait arrêter ses pleurs d'aucune façon, l'Empereur lui dit aussi :

- Tais-toi, mon enfant, car je te donnerai : la jeunesse sans vieillesse et la vie sans mort!

Alors l'enfant se tut et naquit.

(Constantin 1989, 5)

L'auteur, d'autre part, conserve le " schéma tripartite du conte originel - la naissance miraculeuse conditionnée par une promesse inouie, le voyage sur des terres de l'essence et le retour dans le réel » (Popescu 2008, 7). Les titres des chapitres du roman vont dans le même sens : ils démontrent une fois de plus que le caractère et le ton de ce roman doivent beaucoup au conte. Qu'on lise les noms des chapitres : Veuillez donc naître, seigneur mon fils ! L'épée de la Croisade, Un corps pour vaincre, Jeu de masques, et une lettre posthume, Omne solum forti patria!, Le long de gouffres obliques, Un monde de magie et de violence, Le Prince de diamant au combat, Jeunesse sans vieillesse, vie sans mort, Le bâtard éternel, Le marchand de sabres, L'embarquement pour Cythère.

De par l'originalité des thèmes traités, Ilie Constantin a été apprécié en France. En même temps, il apparaît comme l'une des figures fondamentales de la littérature roumaine de l'exil.

4 Interview de Maria Postu avec Ilie Constantin publié 13 juin 2015, disponible en ligne http://www.mariapostu.ro/2015/o7/interviu-cu-poetul-si-prozatorul-ilie.html 


\section{Bibliographie}

Constantin, Ilie. (1969). Coline cu demoni (Collines aux démons). Bucuresti: Editura Eminescu.

Constantin, Ilie. (1983). L’Ailleurs, préface de Virgil Tanase. Paris : Silex.

Constantin, Ilie. (1986). Rivage antérieur. Paris : Le Méridien.

Constantin, Ilie. (1994). Le lettré barbare. Paris : Saint-Germain des Près.

Constantin, Ilie. (1989). La Chute vers le zénith. Paris : Gallimard.

Costantin, Ilie. (1995). Desprinderea de țărm (S’arracher au rivage). Bucuresti: Editura Eminescu.

Dictionarul General al Literaturii Române (C/D), volumul al II-lea. (2005). Bucuresti : Editura Univers Enciclopedic.

Manolescu, Florin. (2010). Enciclopedia exilului literar românesc, 1945-1989. Scriitori, reviste, instituții, organizații. București: Editura Compania.

Pachia Tatomirescu, Ion. (2005). Generația resurecției poetice (1965 1970).Timișoara : Editura Augusta.

Pioras, Valeria. (2003). Les vies parallèles des œeuvres littéraires auto-traduction et réécriture chez Miron Kiropol, Ilie Constantin et Virgil Tănase. Thèse de doctorat, sous la direction de François-Charles Gaudard.

Pop, Ion. (1973). Poezia unei generații. Cluj-Napoca : Editura Dacia.

Popescu, Magdalena. (2008.) "Cum să-nveți să nu mori niciodată şi să-nduri veşnicia", préface du roman Căderea spre zenit (1995). Bucuresti : Paralela 45

Postu, Maria. (2015). "Demnitatea poezii", Cultura, 523: https://revistacultura.ro/ nou/2015/07/demnitatea-poeziei/ 